\title{
Evaluation of different non-chemical wax moth prevention methods in the backyards of rural beekeepers in the North West dry land areas of Ethiopia
}

\author{
Alemu Tsegaye ${ }^{1, \dagger}$, Abebe Jenberie Wubie ${ }^{1, \uparrow, *}$, Addisu Bihonegn Eshetu ${ }^{1, \dagger}$, \\ Meresa Lemma ${ }^{1,}$ \\ ${ }^{1}$ Amhara Region Agricultural Research Institute, Sekota Dryland Agricultural Research Center (SDARC), Wag- \\ Himra, 62 Sekota, Ethiopia \\ ${ }^{\prime}$ Both authors have contributed equally to this work \\ *Abebe Jenberie Wubie is for whom correspondence
}

\begin{abstract}
Wax moths are ubiquitous pests of honey bee colonies that destroy beeswax combs. To study the efficiency of different preventing techniques in local conditions, five treatments were assigned to purposively selected wax moth susceptible colonies. The results have revealed that $66.7 \%$ of the colonies have absconded from control treatments due to wax moth infestation. Colonies assigned to supplementary feeding (with 16391.3 bee population) were significantly better than other treatments in preventing serious wax moth attacks while the control group possessed the lowest value (12588.23). This further elucidated that strong colonies had better strength to defend pest attacks. Even if the overall average number of wax moth infected combs was 1.16 combs per colony, tobacco leaf smoke had the lowest (0.39) infected combs. Furthermore, the control group was the highest in the number of counted wax moth larvae (471) where tobacco leaf smoking was with the lowest value (43). In conclusion, supplementary feeding and appropriate use of tobacco leaf smoke shall be used as a combined recommendation in reducing the damage. Moreover, training of beneficiaries in appropriate use of tested methods and seasonal colony management techniques should be included in the package. Based on the current trends in wax moth damage in the country, studies on all possible safe preventive strategies will be a focus of future national research directions. Thus, this contribution, we believe, will be used as a building block. Of course, attempts in developing a natural enemy against wax moth adults shall keep the balance in the environment as the insect is also beneficial in the ecology.
\end{abstract}

Key Words: wax moth, wax moth attack, infestation, supplementary feeding, wax moth trap, tobacco leaf smoke, absconding, ecology

\section{Introduction}

Greater (Lepidoptera: Pyralidae, Galleria mellonella) and Lesser (Lepidoptera: Pyralidae, Achroia grisella) wax moths are ubiquitous pests of honey bee colonies (Paddock, 1918; Williams, 1997; Gillard, 2009; Ellis et al., 2013). More specifically, wax moths are insects in the order Lepidoptera that can eat and destroy the beeswax combs where the bees can store pollen, honey and lay eggs for their generation continuity (Dessalegn, 2001). Wax moths are opportunists or secondary invaders just waiting for a chance to become established and gain the right hand. Stored combs are ideal places for the breeding of wax moths. Wax moths, as adults, are nocturnal insects that fly at night and hide in dark places during the day (Gillard, 2009). They thrive in dark, warm, poorly ventilated areas that are not well defended by honey bees (Paddock, 1918; Williams, 1997; Ellis et al., 2013). The female wax moth, after entering the hive, laid eggs in the darker and unattended combs, in which the eggs hatch in three days (Arbogast et al., 1980; Chase, 1921; Eischen and Dietz, 1987; Smith, 1965; Warren and Huddleston, 1962). The emerged larvae are, therefore, become important pests of wax combs, especially in stressed colonies, and can cause significant damage to stored beekeeping equipment too (Dessalegn, 2001; Chase, 1921; Eischen and Dietz, 1987; Smith, 1965). They will, in a few moments, begin to eat the wax, make a tunnel through and destroy the comb cells, spins and grow progressively in attacking neighbourhood combs through time which will in turn force the colony to leave the hive. A greater wax moth larva, as an example, molts 7 times throughout its development (Ellis et al., 2013; Chase, 1921; Eischen and Dietz, 1987; Smith, 1965 ) and securing the continuation of life inside the hive.

Currently, wax moths are found in all parts of the country (for example) and found to be the most important ones than honeybee diseases (Dessalegn, 2001). They occur in all beekeeping areas but are becomes more active and spread rapidly in warmer climates (Crane, 2000). In this case, beekeepers everywhere have developed a zero tolerance for wax moth damages. Thus, they should strive to minimize wax moth damage by timely use of good beekeeping pest management practices. The extent of its damage at global level is very huge in causing substantial comb loss, damage to beehive materials, spoils beehive products. However, their effect 
has generally been considered as little damage in areas where temperature is below $25^{\circ} \mathrm{C}$. Colonies weakened by frequent feed shortage, exposed to poor colony management, higher wax moth infestation, subsequent colony swarming may not allow the colony to be able to protect themselves, thus possibly allows penetration by wax moths very easily (Neumann et al., 2013; Ellis et al., 2013; Dietemann et al., 2013). Colony fumigation with cotton cloth, rubbing hive materials with Vernonia spp., colony smoking with tobacco leaf, use of different wax moth traps and so on were some of the non-chemical techniques suggested locally in the control of this pest (Charriere and Imdorf, 1999; Popolizio and Pailhe, 1973; Shimanuki and Knox, 1997; Crane, 2000). Furthermore, various research investigations have been obtained as an effective non-chemical measures to control wax moth attacks in honey bee colonies. Even if the efficiency of these results and their working domains vary greatly due to various factors, use of red fire ants (Hood et al. 2003), B401 (a product from a bacterium, Bacillus thuringiensis subspecies aizawai) (Burges and Bailey, 1968a, b; Ellis and Hayes, 2009; Vandenberg and Shimanuki, 1990), heat and cold treatments to the combs (Hood, 2010), cleaning equipment, old empty boxes and combs (Shimanuki and Knox, 1997) have been suggested and recommended so far (Charriere and Imdorf, 1999; Popolizio and Pailhe, 1973; Shimanuki and Knox, 1997; Crane, 2000), Male sterile technique (MST) (Jafari et al., 2010), fumigation (Burgett and Tremblay, 1979; Cantwell et al., 1972; Goodman et al., 1990). Of course, all possible techniques shall be evaluated and verified in the local conditions too.

The significant economic importance of wax moths has led to a number of investigations on its life history, biology, behaviour, ecology, molecular biology, physiology and control (Sharma et al., 2011; Shimanuki et al., 1992). Furthermore, they have been serving as a model organism for studies in insect physiology, genomics, proteomics, etc using the research methods described for this pest (Ellis et al., 2013, Neumann et al., 2013; Ellis et al., 2013; Dietemann et al., 2013).

Beekeepers have been attempting to control wax moth populations in many ways. This paper is not intended to outline the methods related to controlling wax moths since they vary from region to region, country to country and from season to season (Sharma et al., 2011; Shimanuki et al., 1992). Rather, our work focuses on the evaluation and verification of local and adopted techniques that are useful for non-chemical method of wax moth control. Of course, these techniques might serve as a spring board for further investigation in our context. Even if, there is possibly hundreds of research techniques associated with the control of this insect depending on prevailing conditions in each of the regions/countries, because of the fact that the technological advancements in the country are at their infant stage, we couldn't adopt all the latest research findings performed elsewhere in the world. However, the economic importance of the pest in the country's beekeeping industry and urgency for bringing about some kind of methods in minimizing the effect of wax moth, it is very clear that, looking for options is an immense important activity. Therefore, the need of a significant evaluation of potential nonchemical wax moth control methods in the North West dry lands of the country to assist beekeepers' efforts in their struggle against this pest and in increasing productivity, could be considered as an important activity in livelihood improvement. Thus, the objectives of this experiment were to evaluate and verify different suggested non-chemical wax moth control techniques and recommend a potential wax moth control and/or prevention method in the study area.

\section{Materials and Methods}

Wax moth susceptible sites and willing beekeeper farmers whose colonies were infested by wax moth were purposively selected using different previous survey results, personal observations and stakeholder reports. Colonies which are free from the infestation were purchased and transferred to new and clean beehives. The strength and other factors associated with the honeybee colonies were tried to make similar in order to minimize the effect of human caused errors in this experiment.

The experiment was undertaken using 5 treatments; wax moth trap, supplementary feeding, tobacco leaf smoking, supplementary feeding + wax moth trap and Control were arranged as Treatment 1, 2, 3, 4, and 5 respectively. In this experiment, each of the treatments was having 3 replications within the experimental site (i.e. RCBD design with 5 treatments and 3 replications). Wax moth trap (Treatment 1), as one of the treatments, was prepared according to the standard trap mixture (a cup of water, a cup of sugar, half cup vinegar and one peeled banana) contained in $2 \mathrm{~L}$ plastic bottle and let to ferment for a few days. Upon the application, the plastic bottle was drilled with an inch wide hole at its slope below the neck and hanged on a branch closer to the hive and was observed for its attractant effect to adult wax moths before getting into the hive to breed. Number of moths trapped, number of honeybees trapped (if any) and other relevant data were then collected accordingly. The treatment was maintained for its moistness and attracting gas emitting tendency to allow the treatment to have its maximum service in attracting the adult moth (Figure 1). 


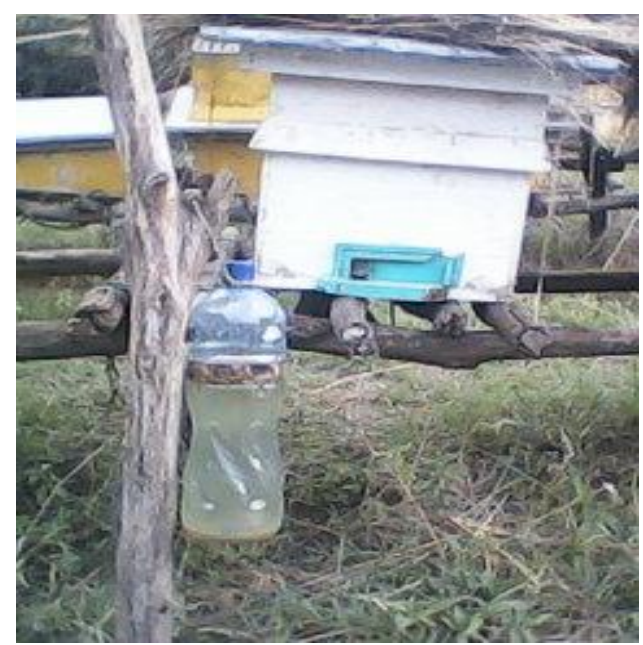

Figure 1: The wax moth trap

Colony strengthening through supplementary feeding $(0.5 \mathrm{~kg}$ of sugar duff or $0.5 \mathrm{~L}$ of sugar solution prepared in $2: 1$ ratio) every 7 days using appropriate feeding techniques without any additional management was used as a second treatment (Treatment 2) (figure 2).

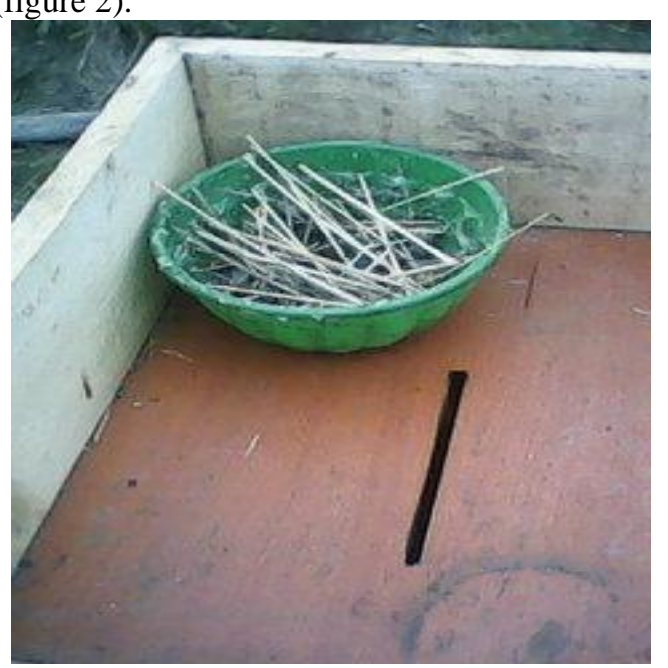

Figure 2: Indoor feeding

Beekeepers indigenous knowledge that they were using to prevent wax moth damage to their colonies, tobacco leaf smoking (Treatment 3), was used as a treatment targeting to study its possible effects on the colonies and evaluation of the technique against wax moths. Here, freshly dried tobacco leaves were used to produce appropriate smoke and were used for 2-3 minutes to fumigate the colony through the hive entrance every 7 days. Consequently, data on the number of dead wax moths (at any stage) and numbers of dead honeybees were collected throughout the experimental period. Furthermore, at the end of the experiment, the moth life stages were monitored for mortality and physiological changes.

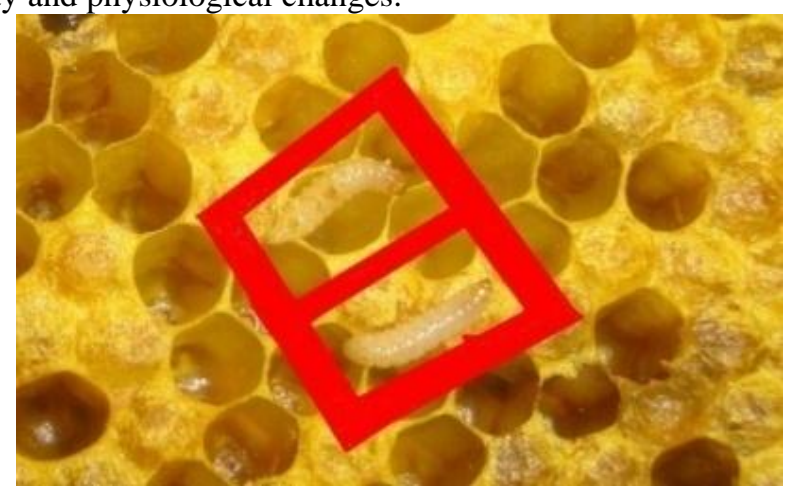

Figure 3: The wax moth larvae

A combination of colony strengthening through supplementary feeding and wax moth trap (Treatment 4) was used as one of the treatments. Finally, a control treatment (farmers' practice) (Treatment 5) was arranged to 
compare and contrast the results of the other treatments. All these treatments were thus arranged in such a way that one treatment group not to affect the other treatment groups.

As most investigations on wax moth control are trying to determine the efficiency of the technique used based on its effects on measurable parameters like mortality rate (death of the wax moth and honey bees at any life stage because of the treatment), trapping efficiency, per cent decrease in honey productivity, etc, this experiment has quantified the results using those data obtained through experimentation. However, in the first year of the experimentation, honey was not harvested from all the treatment colonies. Even though it was predetermined that quantification of actual damage or mortality rates is very difficult in wax moth, dissection of honey bee combs and counting of wax moths were employed to determine the efficiency of the technique used. In this process, even if possible effects to honeybee colonies have been put to the minimum during experimentation as suggested by Delaplane et al. (2013) and Ellis et al., (2013), the effect of each of the treatments on the honeybee colonies were assessed and predetermined. Regular follow up every three days, to observe the general performances of the colonies, data collection and understanding the possible prevailing conditions, were the major activities done throughout experimentation.

\section{Results and Discussions}

Wax moth larvae feed on wax combs, cast larval skins, pollen, and some honey (Shimanuki et al., 1992). Dark combs (combs in which brood has been reared) are preferred by the moth and subsequently suffers the most damage. Moreover, the feeding habits of the larvae reduce the wax combs to a pile of debris, wax moth frass, and webbings. In this experiment, colonies who own old combs or darker in colour, had the highest attack from wax moth in the second year of the study. More specifically, here at this point, we have confirmed that the control groups were having the darker combs which has favoured the intrusion of the wax moth in the colony and led the colony to abscond.

On the other hand, the tunneling and wax comb midrib (the base of the comb) feeding ability of the greater wax moth larvae have damaged the combs permanently and produced silken threads that can trap developing honey bee broods in the comb cells. Even if trapped young emerging honey bees are uncapped from their cells, because of galleriasis, they were observed struggling to emerge but couldn't. As a result, dead young honey bees were observed from those affected colonies. When we see the seriousness of the case, we could emphasize that this condition has agreed with the suggestion given by Williams (1997), who have described the situation that it looks like an entire combs of worker bees that have developed from brood of nearly the same age trapped in this way.

It has been made clear that greater wax moth larvae can cause extensive damage to colony woodenware, including the frames and supers which also have been observed in this experiment. Very serious damages were observed on honey combs and hive frames. When the moth larvae finish feeding, they have been observed that their cocoons were attached. Sometimes some wooden places where the cocoons were attached to, especially the hive frame and cover have been chewed to create an attachment place. This observation was in line with observations explained by (Williams, 1997). And here we have noticed that these chewed wooden parts of the hive were not able to make the hive stable anymore.

In this experiment, out of the total fifteen colonies assigned to the five treatments, $33.33 \%$ of the experimental colonies have absconded due to wax moth infestation resulted from a prolonged and strong dearth period mostly occurring from April to May as a peak. However, the results of this study have indicated that seriously wax moth infected combs appeared to occur starting from January through May. As confirmed, this is related to the prolonged duration of the dearth period when the colony loses its strength and vigor.

Consequently, more number of experimental colonies (two out of three) was absconded from the control group (Figure 4). Of course, colonies were also absconded from trapping treatments. From the results here, it can be confirmed that strong dearth may result with harder pest infestation and poor colony management which caused colony absconding.

The bees need to have an access to all parts of the hive. Combs left unattended by bees have been attacked by wax moths. The combined analyses of variance over years (Table 3) indicated that the number of frames covered (regularly attended) by bees was significantly higher for the colonies assigned to treatment 2 $(8.19 \pm 1.96)$ followed by treatment $4(8.09 \pm 1.67)$ and treatment $3(7.60 \pm 1.95)$. Treatment 1 and the control group (treatment 5) have shown relatively the lowest number of frames with bees which made these treatments to own weak colonies (Table 3). This may be attributed to, the trap as an attractant, was not trapping the moths as hypothesized. As, the treatment (trap) was designed in different agro ecology and weather conditions, its low trapping efficiency also maybe because of unknown and variable environmental factors. However, even if it was not the objective of the experiment, during experimentation, as suggested by different results, we have been observing that placement of a light source in night nearby the trap for a while was assisting the trapping efficiency significantly. 
Even if the honey bees could have the capacity to prevent any pest intrusion to the colony when they are in their active season and when they are strong, the overall average honey bee population in a hive (14790.21) recorded in this experiment was not found to be able to prevent the wax moth attack in the study area on an average. Whereas, the colonies assigned to feeding (treatment 2), which were with the maximum honey bee population $(16391.3 \pm 3924.16)$, were significantly better than other treatments in preventing serious wax moth attacks followed by treatments 4,3 and 1 which were with an overall average population of $16225.35 \pm$ $3356.00,15207.5 \pm 3909.35$ and $13148.14 \pm 3217.9$ respectively (Table 3 ). The lowest honey bee population was recorded from the control group (12588.23). As a result, this treatment was the first to lose its two colonies out of the three because of the reason that lower bee population couldn't attend the combs in the hive which in turn gave an access for the wax moth to enter the hive.

Moreover, colonies that have become weak and are with low adult bee population tends to be weak in their strength and have been observed being unable to guard their hive effectively against any kind of pest attacks. Therefore ensuring active and populous colonies with feeding are playing an important role in preventing dangerous infestations from wax moths.

In this experiment, the overall average number of wax moth infected combs in a colony was found to be 1.16 combs which was higher than average infected combs (0.9) reported by Amsalu et al (2011) (Table 3). However, the numbers of wax moth infected combs were higher than 1.0 on average for both experimental years (Table $1 \& 2$ ). As this report has been generated from another part of the same country, it is further magnifying that ecological differences have their own impact on the rate and seriousness of wax moth attack to a given colony. Among the treatments, the lowest average wax moth infected combs was recorded from the colonies assigned to treatment $3(0.39)$ while the highest number of infected combs was recorded from the colonies assigned to the control group (1.73) followed by treatment 1 (1.37) (Table 3). Furthermore, colonies assigned to treatment 3 were the only ones which didn't show a wax moth infected combs during the second year of the experiment (Table 2). Here, as it has been observed in the study period, the trap which was not accompanied with a light source in the late evenings for a while was not successful in the prevailing conditions in the study area.

Regarding the number of adult and larval wax moths counted in the hives because of the lower efficiencies of the treatments, treatment 5 has revealed the maximum number of wax moths (471) in the colonies followed by treatment 1 (347). However, treatment number 3 was with the lowest number counted (43) during the experimental period followed by treatments $2 \& 4$ chronologically. Here, though the variation might be due to some other reasons, the pupal stage of the wax moth was protected by the cocoons from dying out. This observation was clearly visible in treatment 3 colonies as the smoke was not able to kill the already established cocoons.

According to the data obtained from this experiment regarding colony's honey yield, colonies were able to produce an average of $10.51 \mathrm{~kg}$ of honey per colony per season (Table $3 \& \mathrm{Fig} 4$ ). This result was lower than an average productivity of colonies (10.56 kg/colony) reported by Amsalu et al (2011). Even though this might be attributed to the flowering potential of the experimental sites and management styles, the results were insignificantly different with this similar experiment from another location. Moreover, treatments showed a significant difference in honey productivity among themselves $(\mathrm{p}<0.05)$ (Table 3). Accordingly, the highest honey yield productivity $(26.5 \mathrm{~kg}$ ) was recorded from colonies assigned to treatment 2 followed by treatment 4 $(17.5 \mathrm{~kg})$ and treatment $3(14.9 \mathrm{~kg})$. The lower honey productivity in this experiment was expected to be because of the fact that the treatments were located around the homestead areas where the vegetation cover were relatively low compared to the higher colony density in the area. As indicated in Table 3, no honey was harvested from the colonies assigned to the control treatment during the whole experimental period.

Table 1: Mean frames covered by bees, bee population and infected combs in the experimental colonies in the first year

\begin{tabular}{|c|c|c|c|}
\hline Treatments & $\begin{array}{c}\text { Frames covered by } \\
\text { bees }\end{array}$ & Bee population & Infected combs \\
\hline Trapping & $6.87 \pm 1.46^{\mathrm{b}}$ & $13733.3 \pm 2912.87^{\mathrm{b}}$ & $1.38 \pm 0.62^{\mathrm{a}}$ \\
\hline Feeding & $8.13 \pm 1.94^{\mathrm{a}}$ & $16250.71 \pm 3893.75^{\mathrm{a}}$ & $1.03 \pm 0.88^{\mathrm{b}}$ \\
\hline Tobacco smoking & $7.73 \pm 2.04^{\mathrm{a}}$ & $15470.58 \pm 4099.04^{\mathrm{a}}$ & $0.39 \pm 0.67^{\mathrm{c}}$ \\
\hline Feeding + Trapping & $8.47 \pm 1.48^{\mathrm{a}}$ & $17000.00 \pm 2966.48^{\mathrm{a}}$ & $1.05 \pm 0.86^{\mathrm{b}}$ \\
\hline Control & $6.39 \pm 1.48^{\mathrm{b}}$ & $12947.87 \pm 2958.7^{\mathrm{b}}$ & $1.74 \pm 0.94^{\mathrm{a}}$ \\
\hline Mean & 7.54 & 15103.03 & 1.12 \\
\hline $\mathrm{P}<0.05$ & $* *$ & $* *$ & $*$ \\
\hline
\end{tabular}


Table 2: Mean frames covered by bees, bee population and infected combs in the experimental colonies in the second year

\begin{tabular}{|c|c|c|c|c|}
\hline Treatments & $\begin{array}{c}\text { Frames covered by } \\
\text { bees }\end{array}$ & Bee population & Infected combs & Honey yield \\
\hline Trapping & $6.13 \pm 1.37^{\mathrm{b}}$ & $13222.2 \pm 3059.33^{\mathrm{b}}$ & $1.36 \pm 0.67^{\mathrm{a}}$ & $11.15 \pm 10.11^{\mathrm{bc}}$ \\
\hline Feeding & $8.36 \pm 2.06^{\mathrm{a}}$ & $16714.28 \pm 4121.77^{\mathrm{a}}$ & $0.93 \pm 1.03^{\mathrm{ab}}$ & $26.5^{\mathrm{a}}$ \\
\hline Tobacco smoking & $7.37 \pm 1.8^{\mathrm{a}}$ & $14736.84 \pm 3603.11^{\mathrm{a}}$ & $0.00 \pm 0.00^{\mathrm{c}}$ & $14.9 \pm 6.5^{\mathrm{b}}$ \\
\hline Feeding + Trapping & $7.71 \pm 1.79^{\mathrm{a}}$ & $115428.57 \pm 3583.34^{\mathrm{a}}$ & $1.00 \pm 0.87^{\mathrm{b}}$ & $17.5 \pm 9.19^{\mathrm{b}}$ \\
\hline Control & $6.00 \pm 1.8^{\mathrm{b}}$ & $12416.67 \pm 3437.85^{\mathrm{b}}$ & $1.72 \pm 0.82^{\mathrm{a}}$ & $0.00 \pm 0.00^{\mathrm{c}}$ \\
\hline Mean & 7.11 & 14115.70 & 1.00 & 10.51 \\
\hline P<0.05 & $* *$ & $* *$ & $*$ \\
\hline
\end{tabular}

Table 3: Mean frames covered by bees, bee population and infected combs in the experimental colonies combined over years

\begin{tabular}{|c|c|c|c|c|}
\hline Treatments & Frames covered by bees & Bee population & Infected combs & Honey yield \\
\hline Trapping & $6.53 \pm 1.43^{\mathrm{b}}$ & $13148.14 \pm 2947.38^{\mathrm{b}}$ & $1.37 \pm 0.63^{\mathrm{ba}}$ & $11.15 \pm 10.11^{\mathrm{bc}}$ \\
\hline Feeding & $8.19 \pm 1.96^{\mathrm{a}}$ & $16391.3 \pm 3924.16^{\mathrm{a}}$ & $0.98 \pm 0.92^{\mathrm{bc}}$ & $26.5^{\mathrm{a}}$ \\
\hline Tobacco smoking & $7.60 \pm 1.95^{\mathrm{a}}$ & $15207.5 \pm 3909.35^{\mathrm{a}}$ & $0.39 \pm 0.63^{\mathrm{c}}$ & $14.9 \pm 6.5^{\mathrm{b}}$ \\
\hline Feeding + Trapping & $8.09 \pm 1.67^{\mathrm{a}}$ & $16225.35 \pm 3356.00^{\mathrm{a}}$ & $1.02 \pm 0.86^{\mathrm{bc}}$ & $17.5 \pm 9.19^{\mathrm{b}}$ \\
\hline Control & $6.25 \pm 1.65^{\mathrm{b}}$ & $12588.23 \pm 3217.9^{\mathrm{b}}$ & $1.73 \pm 0.88^{\mathrm{a}}$ & $0.00 \pm 0.00^{\mathrm{c}}$ \\
\hline Mean & 7.37 & 14778.18 & 1.16 & $* .51$ \\
\hline P<0.05 & $* *$ & $* *$ & $*$ \\
\hline
\end{tabular}

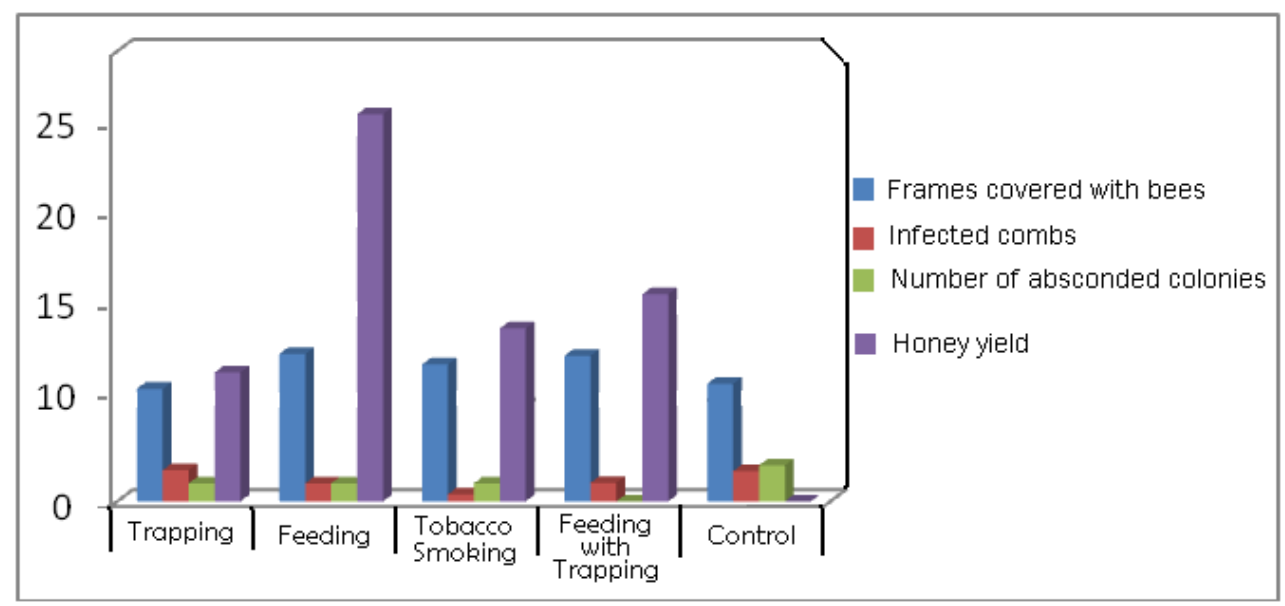

Figure 4: Mean of honeybee colonies absconded, number of infected combs, frames covered by bees and honey yield recorded

\section{Conclusion and recommendations}

Wax moths remain a frustrating source of problems for beekeepers and honey bee colonies in the globe and country at large and the study area in particular. Recently, the number of investigations related to wax moth control has dropped significantly without suggestions referring to applicable backgrounds for developing countries who are attempting to supply organic hive products. This might be largely due to the perception of wax moths as a secondary pest of the bee colonies and their importance in rural beekeeping farmers in those developing countries. Regardless of this fact, wax moths remain as an important test model for entomologists, physiologists, and investigators from other disciplines. Based on current trends in wax moth research and the 
huge damage happening to the beekeeping industry in the country like Ethiopia, we expect that the usefulness of studying all possible safe wax moth preventive and damage control strategies will continue as an area of interest to researchers permanently in the future national research directions. Attempting the usefulness of our study to this direction and because of its sense of urgency, we strongly believe that this study will give a springboard for the upcoming research agendas in the near future.

Although we have used certain methods associated with preventing wax moth attacks in this paper, as the experiment was conducted in the farmers' backyard which couldn't allow us to bring all the factors similar to all the treatments because of various uncontrolled phenomenon, still there remain methodological gaps for this important pest of the honey bees under the local conditions. Furthermore, such a study may seem like an easy task, but it was not able to bring all the possible actual effects of all the treatments especially for trapping method used. We also have discovered that not only none of our methods have helped us but also no proper methods are available to quantify the number of moths in each of the growing stages and quantify the exact losses because of the attacks at local conditions. It was also very difficult to calculate the benefits of each of the techniques with their associated outcomes.

At this point, we further would like to suggest that the damage from this pest to honey bee colonies in the country as a whole and in the study area in particular shall take the prior attention in future honey bee pest control research with a broad, non-chemical effective preventive method development strategies. These studies should also focus in the control of the appropriate target (growth stage) which is causing the damage rather than focusing on the control of the adult which seems like un-reliable to stop entering the hive. Of course, development of a natural enemy against wax moth adults is another issue of research paying due attention that the moth is also an important insect in protecting our ecology through pollination and other benefits. Thus, these are but a sample of methods that should require further verification in a standardized recommendation to prove the usefulness to researchers, especially those investigating wax moths from an apicultural perspective.

Accordingly, the prevention methods, that we have tested in this study against wax moth attack, have indicated that supplementary feeding to ensure more colony population and bring about vigorous colonies that can safe guard their hives against wax moth by themselves and colony fumigation with tobacco leaf smoke for lower wax moth infestation have to be used as ready-to be-used combined recommendation unlike the undetermined effects of tobacco smoke to honey and other hive products. Of course, as excess use of tobacco leaf smoke is an irritant to the bees themselves, care should be taken not to smoke for more than 2-3 minutes and with a maximum intensity of 5-10 puffs of smoke.

Regarding applied methods in the wax moth research, we know that there are plenty of research methodologies related to basic investigations like wax moth physiology, genomics and proteomics. However, we are confident that adding these early stage verified preventive methods through our paper to the research background could be an energy for the upcoming entire documentation (like that of the BEEBOOK) to be compiled on wax moth research and control methods which could include lots of references on its comprehensive bibliography literatures.

Bearing in mind that colony management is the most and foremost important activity in beekeeping, here in our study, it has been cleared that use of combined treatments in preventing and controlling this pest (such as reducing un-occupied frames, supers and infected combs during dearth periods, maintain healthy, strong colonies to fit to a bee-to-comb ratio, cleaning of the hive and its surroundings on a regular basis, appropriate use of cold and heat treatments and replacing old combs regularly) will increase the chance of success.

In line with the results of this study and other recommendations, we also would like to note down that training of beneficiaries with appropriate use of tested methods and seasonal colony management techniques with plantation and appropriate use of tobacco leaf smoke would help for emergency cases against wax moth attacks.

\section{References}

[1]. Amssalu et al, (2011) Management practices to prevent wax moth, a pest of honeybees HBRC, Holleta, Ethiopia

[2]. Arbogast, R.T, Leonard lecato, G, Van Bayrd, R (1980) External morphology of some eggs of stored-product moths (Lepidoptera: Pyralidae, Gelechiidae, Tineidae). International Journal of Insect Morphology and Embryology 9(3): 165-177. ISSN: 0020-7322 http://dx.doi.org/10.1016/0020-7322(80)90013-6

[3]. Burges, H; Bailey, L (1968a) Persistence of Bacillus thuringiensis in foundation beeswax and beecomb in beehives for the control of Galleria mellonella. Journal of Invertebrate Pathology 28(2): 217-222. http://dx.doi.org/10.1016/0022-2011(76)90125-7

[4]. Burges, H; Bailey, L (1968b) Control of the greater and lesser wax moths (Galleria mellonella and Achroia grisella) with Bacillus thuringiensis. Journal of Invertebrate Pathology 11(2): 184-195. http://dx.doi.org/10.1016/0022-2011(68)90148-1

[5]. Burgett, D M; Tremblay, A (1979) Controlled release fumigation of the greater wax moth. Journal of Economic Entomology 72 : 616-617.

[6]. Cantwell, G E; Jay, E; Pearman Jr, G P; Thompson, J (1972) Control of the greater wax moth, Galleria mellonella (L.), in comb honey with carbon dioxide: Part I. American Bee Journal 112: 302-303.

[7]. Charriere, J-D; Imdorf, A (1999) Protection of honey combs from wax moth damage. American Bee Journal 139(8): 627-630. 
[8]. Chase, R W (1921) The length of the life of the larva of the wax moth, Galleria mellonella L., in its different stadia. Transactions of the Wisconsin Academy of Sciences, Arts and Letters 20: 263-267.

[9]. Crane A (2000) Prevention and treatment of disease and pests of honeybees; the world picture, Newzland beekeeper

[10]. Delaplane, K S; Van Der Steen, J; Guzman, E (2013) Standard methods for estimating strength parameters of Apis mellifera colonies. In V Dietemann; J D Ellis; P Neumann (Eds) The COLOSS BEEBOOK, Volume I: standard methods for Apis mellifera research. Journal of Apicultural Research 52(1): http://dx.doi.org/10.3896/IBRA.1.52.1.03

[11]. Desalegne B (2001) Origin and characterization of honeybee (A. melifera) pollen source around Utrecht University, The Netherlands. M.sc thesis, Utrecht University, Faculty of Biology, Department of behavioural social inset unit

[12]. Dietemann, V; Nazzi, F; Martin, S J; Anderson, D; Locke, B; Delaplane, K S; Wauquiez, Q; Tannahill, C; Frey, E; Ziegelmann, B; Rosenkranz, P; Ellis, J D (2013) Standard methods for varroa research. In V. Dietemann; J D Ellis; P Neumann (Eds) The COLOSS BEEBOOK, Volume II: standard methods for Apis mellifera pest and pathogen research. Journal of Apicultural Research 52(1): http://dx.doi.org/10.3896/IBRA.1.52.1.09

[13]. Eischen, F A; Dietz, A (1987) Growth and survival of Galleria mellonella (Lepidoptera: Pyralidae) larvae fed diets containing honey bee-collected plant resins. Annals of the Entomological Society of America 80: 74-77.

[14]. Ellis, A M; Hayes, G W (2009) Assessing the efficacy of a product containing Bacillus thuringiensis applied to honey bee (Hymenoptera: Apidae) foundation as a control for Galleria mellonella (Lepidoptera: Pyralidae). Journal of Entomological Science 44(2): 158-163.

[15]. Ellis, J.D., J.R Graham and A. Mortensen (2013) Standard methods for wax moth research, Journal of Apicultural Research 52(1): (2013). DOI 10.3896/IBRA.1.52.1.10

[16]. Gillard, G (2009) My Friend, the Wax Moth, Amer. Bee J. Vol. 149 no. 6, pp 559-562.

[17]. Goodman, R; Williams, P; Oldroyd, B; Hoffman, J (1990) Studies on the use of phosphine gas for the control of greater wax moth (Galleria mellonella) in stored honey bee comb. American Bee Journal 130: 473-477

[18]. Hood M (2010) Wax Moth IPM, Bee Culture magazine, vol. 138, no. 9 \& 10

[19]. Hood, W M; Horton, P M; Mccreadie, J W (2003) Field evaluation of the red imported fire ant (Hymenoptera: Formicidae) for the control of wax moths (Lepidoptera: Pyralidae) in stored honey bee comb. Journal of Agricultural and Urban Entomology 20(2): 93103 .

[20]. Jafari, R; Goldasteh, S; Afrogheh, S (2010) Control of the wax moth Galleria mellonella L. (Lepidoptera: Pyralidae) by the male sterile technique (MST). Archives of Biological Sciences 62(2): 309-313. http://dx.doi.org/10.2298/ABS1002309J

[21]. Neumann, P; Pirk C W W; Schäfer, M O; Ellis, J D (2013) Standard methods for small hive beetle research. In V Dietemann; J D Ellis, P Neumann (Eds) The COLOSS BEEBOOK: Volume II: Standard methods for Apis mellifera pest and pathogen research. Journal of Apicultural Research 52(4): http://dx.doi.org/10.3896/IBRA.1.52.4.19

[22]. Paddock, F B (1918) The beemoth or waxworm. Texas Agricultural Experiment Station; USA. 44 pp.

[23]. Popolizio, E.R. and L.A. Pailhe (1973) Storing combs in "wax-moth-safe" storage rooms. Proceedings of the 24th International Apicultural Congress. Pp. 382-383.

[24]. Sharma, V; Mattu, V K; Thakur, M S (2011) Infestation of Achoria grisella F. (wax moth) in honey combs of Apis mellifera L. in Shiwalik Hills, Himachal Pradesh. International Journal of Science and Nature 2(2): 407-408.

[25]. Shimanuki, H. and D.A. Knox (1997) Summary of Control Methods. In Honey Bee Pests, Predators, \& Disease, 3rd Edition, Editors R.A. Morse \& K. Flottum, Published by A.I. Root Company, pp.505-507.

[26]. Shimanuki, H; Knox, D; Furgala, B; Caron, D; Williams, J (1992) Diseases and pests of honey bees In J M Graham (Ed.). The hive and the honey bee. Dadant and Sons; Hamilton, IL, USA. pp. 1083-1151.

[27]. Smith, T L (1965) External morphology of the larva, pupa and adult of the wax moth Galleria mellonella L. Journal of the Kansas Entomological Society 38: 287-310.

[28]. Vandenberg, J; Shimanuki, H (1990) Application methods for Bacillus thuringiensis used to control larvae of the greater wax moth (Lepidoptera: Pyralidae) on stored beeswax combs. Journal of Economic Entomology 83: 766-771.

[29]. Warren, L; Huddleston, P (1962) Life history of the greater wax moth, Galleria mellonella L., in Arkansas. Journal of the Kansas Entomological Society 35: 212-216.

[30]. Williams, J L (1997) Insects: Lepidoptera (moths). In R Morse; K Flottum (Eds). Honey bee pests, predators, and diseases. The AI Root Company; Ohio, USA. pp. 121-141. 